\title{
Automated smart car parking system for smart cities demand employs internet of things technology
}

\author{
Rahman Atiqur \\ Information and Communication Engineering, Chongqing University of Posts and Telecommunications, China
}

\begin{tabular}{|c|c|}
\hline Article Info & ABSTRACT \\
\hline Article history: & The use of smart cities rises quickly with the fast progress of the Internet of \\
\hline Received Apr 20, 2020 & $\begin{array}{l}\text { Things (IoT) advances. The smart city idea essentially getting city life; as } \\
\text { well raises the capability of municipal jobs and facilities plus form viable }\end{array}$ \\
\hline Revised Oct 25, 2020 & economic progress of the city. The point of convergence of this paper is to \\
\hline Accepted Feb 5, 2021 & $\begin{array}{l}\text { introduce an automated smart automobile parking system for smart cities } \\
\text { demand employs internet of things (IoT) technology. The offered automobile }\end{array}$ \\
\hline Keywords: & $\begin{array}{l}\text { parking system covers an IoT entity sent nearby for getting sorted out the } \\
\text { existing parking spots which are quicker contrasted with different }\end{array}$ \\
\hline $\begin{array}{l}\text { Communication technologies } \\
\text { Internet of things (IoT) }\end{array}$ & $\begin{array}{l}\text { frameworks. It is a viewpoint gave as an iOS application for reservation, } \\
\text { entrance, supervision, and leaving the car park places. }\end{array}$ \\
\hline
\end{tabular}

This is an open access article under the $\underline{C C B Y-S A}$ license.

Radio frequency identification

Smart billing

Smart car parking system

Smart city

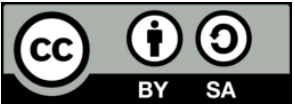

Corresponding Author:

Rahman Atiqur

School of Information and Communication Engineering

Chongqing University of Posts and Telecommunications

Chongqing, 400065, P.R. China

Email: bulbul.cse.cu@gmail.com

\section{INTRODUCTION}

The idea of Smart Towns has grown rapidly in the last couple of years [1]. The goal of building 10 Bangladeshi's Smart Towns can simply be attained, with the widespread progress of ICT Set-up and Internet of Things (IoT) assistances. Nevertheless, one of the protuberant problems faced by individuals in smart towns is the lack of automobile parking facilities and transportation management [1].

The figure of vehicles on the street is growing step by step exponentially due to the advent progress of the municipal population. Conferring to an analysis, In Bangladesh, Dhaka has the maximum quantity of four-wheeler automobiles at 20 lacs, which is flourished by 11 lacs in Chittagong, 70 thousand in Rajshahi, 30 thousand in Khulna, and 20 thousand in Shylet. From the beyond data obviously, conclude the call for parking set-up. In demanding towns like Dhaka as well as Chittagong, there exists no parking system which leads to serious traffic congestion. The drivers incline to travel everywhere in examine of parking cars which ultimately primes to traffic bottlenecks [1].

The examining nearby aimed at parking lead towards enlarging the consumption of Gasoline/Diesel which ultimately causes smog then touches the atmosphere. Mishap likelihoods incline to rise as the carter's attention would be half employed in examining parking [1]. A Smart Parking system is an Internet of Things (IoT) centered parking system in which drivers be able to discover empty parking slots simply using their Smart Phone [1]. A smart car parking system as well allows the driver aimed at the online reservation of a parking slot. The key indication following this theory is the mobilized provision of Dhaka city parking spaces without any human involvement. The anticipated system helps the driver to reserve their parking spaces online, by observing the parking places on an immediate basis for their convenience. 
In Section 2 we talk about the system model in the Dhaka city parking space. Section 3 presents the Smart Car Parking Algorithms and defines in what way they Works. Section 4 provides an indication of all hardware modules used in my systems. Section 5 describes the performance of the system compared to other existing systems and Section 6 concludes the paper.

\section{SMART CAR PARKING SYTEM WORKING ARCHITECTURE}

For developing an application for creating the automobile parking enhanced experienced, elastic as well as protected, I developed a system model that is displayed in the under Figure 1 [1]. This recommended model taking a Raspberry pi 4 panel, this panel is tiny but it operates like an all-purpose PC. The whole central processing unit (CPU) interchanged by this meek debit card-sized panel and it is accessible for lesser costs in the bazaar. This will usage Raspbian (small OS), like a Linux-centered setting. It will perform as a server too for minor applications. With this system expanding Internet of Things (IoT) tools, we can entrance, accomplish as well as link things tenuously.

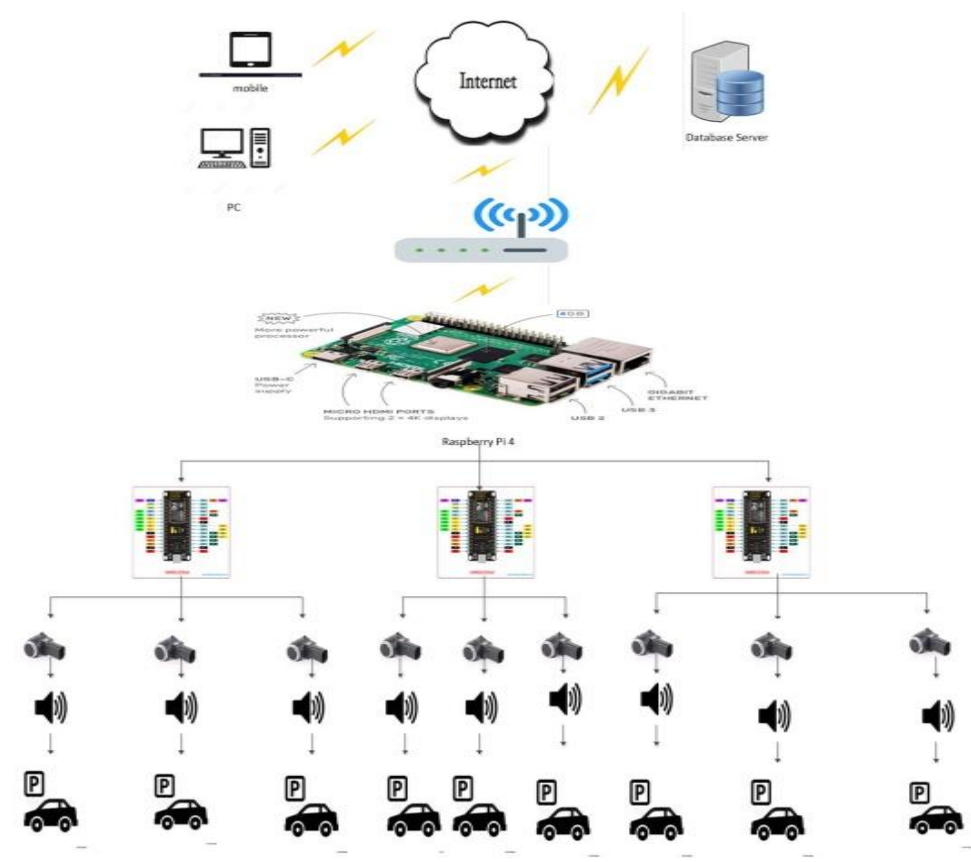

Figure 1. Proposed system model

The operator browses the application using his/her cellular device for a parking slot in a parking range. At this time Ultra-sonic parking sensors are cast-off for perceiving a parking slot. If the operator found a slot, then he/she parked his/her automobile. If he parked a wrong slot a sound is play alarming that wrong parking place you are selected. This system is made of different units to do parking supervision. Those are 'online reservation system', 'parking entrance system', 'parking leaving system', and parking controlling system [2]. The operator faces the trouble of discovering the parking spaces in as well as around the town for resolving that tricky, I advanced an algorithm 'online reservation system' from this operator can reserve the slots beforehand like to reserve an online railway coupon that is presented in algorithm 1 . When the automobile appears at the parking spot then it contracts with the parking management unit. At this time Radio Frequency Identification (RFID) technology is inured to identify the license plate, automobile information at first tested with a record server for foreseeing that car stealing or not. If the license plate ties, then the system will send a voice to the adjacent law enforcement agency for sending messages. I developed a 'parking entry system' that is shown in algorithm 2. If the operator desires to leave the parking spot, the operator needs to pay the parking charge either online or offline that will be copied by the 'parking leaving system', which is presented in algorithm 4. Occasionally the operator puzzles to park his automobile in a specified allocation, he/she may wrongly park as well as while parking his automobile he/she can damage others automobiles also that creates owner mad and we can't catch him/her at all, for resolving this difficulty I advanced 'parking supervision method' that is presented in algorithm 3. From this operator can pay care to park perfectly and if 
broken that will be projected from the record. These all information constantly modernized in the record using the network connection. The system authority can see the record with the admin login iOS application function as well as operators can reserve the spaces thru login to the installed iOS application [3].

\section{SMART CAR PARKING SYSTEM ALGORITHMS AND THEIR WORKING SYSTEM}

\subsection{Parking an online booking system}

It is problematic to discover a parking spot in urban areas during pick hours. That's why here I proposed an online parking space booking system. With the help of these operators can reserve the parking slots beforehand like railway tickets reservation online. Using mobile/laptop application users can book the parking slots. The below algorithm explained the booking process. Users get the parking availability information provides by the Database server; if there are any empty slots obtainable then the operator can reserve the interesting slot and complete the costs and confirm the reservation slots. If an operator does not find the vacant slots then after some time he/she can request again for vacant slots. After finishing the booking, the database is simplified with existing accessibility [4].

Algorithm 1 for parking online booking systems:

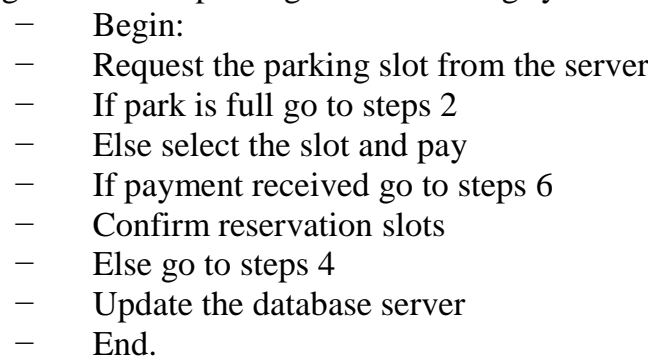

\subsection{Parking entry method}

This parking entrance method customs an Ultrasonic Parking Sensor, Servo motor, LED show, as well as an RFID reader. Ultrasonic Sensor is cast-off to know the existence of automobile for parking, Servo motor is cast-off to exposed the door, LED is cast-off to show the parking information, as well as RFID reader, is cast-off to perceive the automobile particulars like a license plate, model number, holder name, etc. After perceiving the license plate, it will be tested with the stealing list, the stealing list will be delivered by the law enforcement agency and the list will be kept in a record. If that ties with the present license plate at that time a text directed to the law enforcement agency and if it does not then proceed. If the operator reserved online his/her parking slot, then the gate is unlocked as well as he/she can travel inside. The LED shows the chosen parking slot as well as parking condition too. These allocation details constantly simplified to record server. If the operator is not reserved the parking slots beforehand, then he/she checked accessibility from the recording server. If the park is not full then he/she can park his car on-site after paying the parking fee and LED red is 'on'. If the park is filled then a message is displayed alike "try after some time" [5]. All things are described in the following algorithm.

Algorithm 2 for parking entry methods:

- Begin:

- If ultrasonic parking sensor detected go to steps 3

- $\quad$ Read the RFID Tag

- If the car is thefted go to steps 5

- Inform the police

- $\quad$ Else if the slot is prebooked go to steps 7

- $\quad$ Gate opened go to steps 14

- $\quad$ Else check availability from database server then go to steps 9

- If park is full go to steps 10

- $\quad$ Display, try after some times then go to 14

- $\quad$ Else assign the slot and LED red is ON then go to steps 12

- $\quad$ Open the gate then go to steps 14

- $\quad$ Else go to steps 1

- End.

\subsection{Parking supervision method}

This division offers instructions to the proprietors to gardens their cars properly. Here per slot assigned by one Ultrasonic Parking sensor duos, one RFID reader, 3 LEDs, as well as a speaker. Firstly it 
will check the slot is allocated or not, if it is allocated, then LED green goes 'on'. If any automobile comes in the parking slot, at that time Ultrasonic Parking Sensor notices, LED red goes 'on' and LED green turned 'off' and if it does not then LED green turned 'on'. Now RFID reader reads out the automobile's RFID label, if selected automobile RFID does not tie with existing identified automobile RFID then the speaker is 'on' if not open the door and park the automobile. If the speaker on the operator can realize he/she parked his/her automobile wrongly then he/she can leave the slot and goes to his/her chosen slot. This information always simplified in the recording server [6]. The following algorithm is for the parking supervision method.

Algorithm 3 for parking supervision methods:

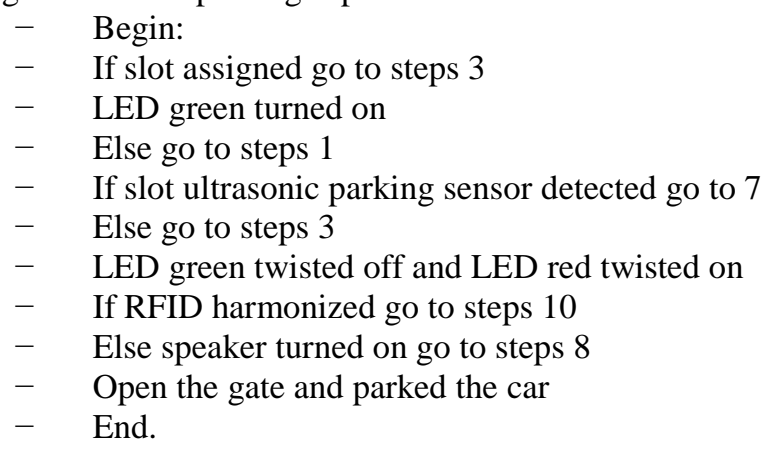

\subsection{Parking leaving method}

This parking leaving method encompasses peripherals parallel towards the parking entrance system. If the car gone from the parking slots, then LED green goes 'on' and simultaneously LED red goes 'off'. At leaving time, the RFID reads the automobile details and displays the parking charge. The parking fee is the operator's option, he/she can pay either online or offline [7]. Since he/she completed the reimbursement either online or offline then the gate opens and he/she can exit from the slot and all the data uploaded to the database server. The given algorithm shows all the things.

Algorithm 4 for parking leaving methods:

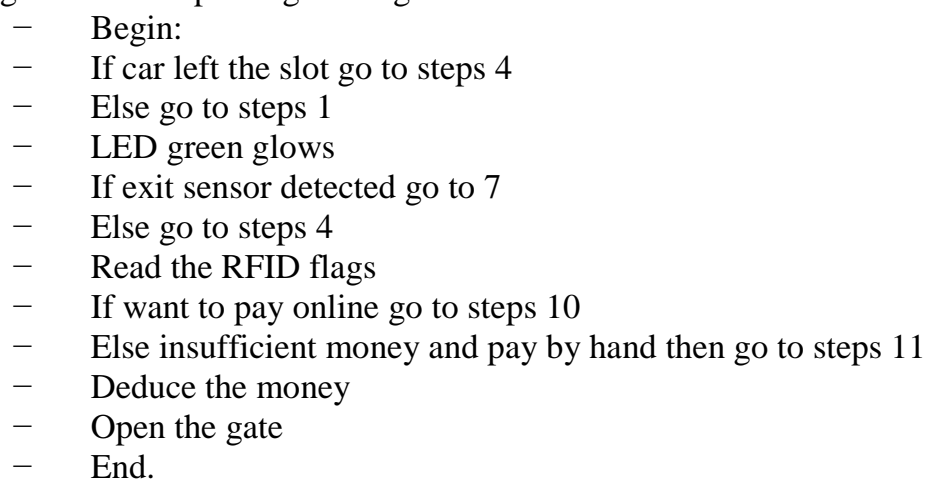

\section{HARDWARE ASPECTS}

\subsection{Node MCU V-3}

NodeMCU version-3, as shown in Figure 2, is an expansion board that turns on the ESP8266 by the Express if Non-Operating System s/w development kit and h/w centered on the ESP-12 unit [8]. The main topographies of the device are $80 \mathrm{x} 106 \mathrm{~Hz}$ of the system clock, 4x106 B of flash memory, about 50000 of operational RAM as well as an on-chip wireless fidelity (wi-fi) Transceiver. The NodeMCU v3 scheme features a 4x106 B (32 MegaByte) flash memory structured in sectors of 4000 respectively. The flash memory address starts at $0 \mathrm{X} 40100000$ besides can be read as well as written from a Zerynth package consuming the internal flash unit. The interior flash of NodeMCU version-3 can be structured in diverse techniques. The usual non-FOTA VM with the VM program starting at 0X0000, afterward the esp8266 pic at 0X20000, and the esp_init_data at 0X3fc000. Rule to the NodeMCU vrsion3 is provided thru the on-board USB Micro B connector or acquiescently by the "VIN" pinch. The electric source is designated routinely. The hardware can run on a power source of 6 to 20 volts. If consuming more than $12 \mathrm{~V}$, the voltage controller may burn and harm the device. The recommended choice is $7 \mathrm{~V}$ to $12 \mathrm{~V}$ [8]. 


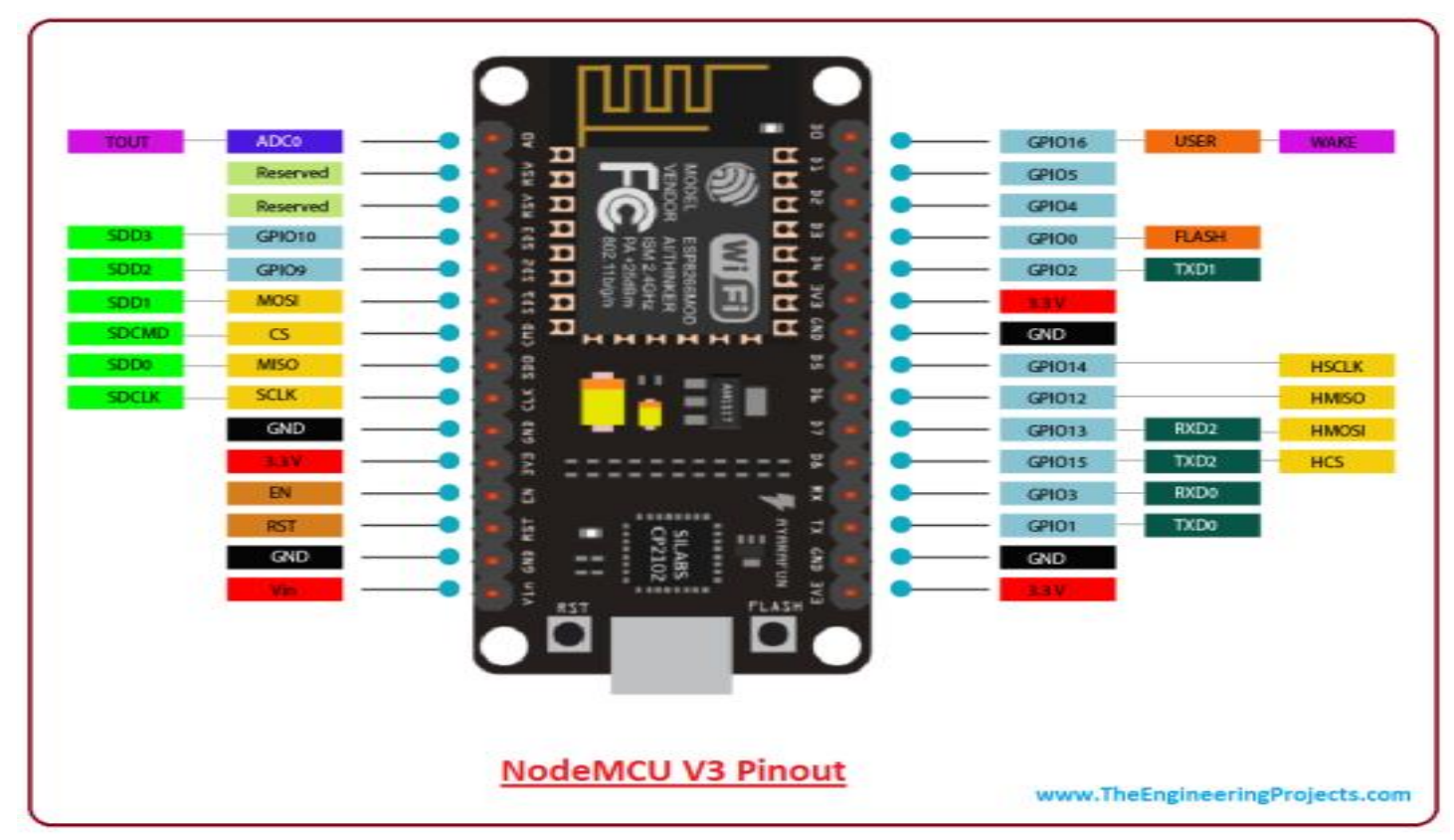

Figure 2. Node MCU development board

Table 1 displays the specifications of a NodeMCU version-3 development board. From here we see that NodeMCU is a 32-bit RISC processor-based device. It has 64 Kilo-Byte RAM. Its clock speed lies around 90 mega-hertz and operational voltage are nearby 3.3 voltage as well as its operational current are 90 mAmp. It has 16 pins for connection.

Table 1. Nodemcu V3 specifications

\begin{tabular}{cc}
\hline Specifications & Values \\
\hline MCU & Tensilica 32-bit RISC CPU Xtensa LX106 \\
RAM & $64 \mathrm{~KB}$ \\
Clock Speed & $90 \mathrm{MHz}$ \\
Operational Voltage & $3.3 \mathrm{~V}$ \\
Operational Current & $90 \mathrm{~mA}(\mathrm{Avg})$ \\
Existing GPIO Pinches & 16 \\
\hline
\end{tabular}

\subsection{An ultrasonic parking sensor}

The concept after the ultrasonic parking sensor is centered on echolocation [9, 10]. The rate of recurrence of the sound is so extraordinary that men can't perceive it, which is beneficial for the reason that it offers accuracy and ruins normal. As sound hits a concrete entity, after creating an echo it is echoed back. As the rapidity of sound is familiar and stable for parallel circumstances, it is likely to pick the distance of the entity you get an echo from by enlarging the quickness of sound by half the time it receipts to perceive the echo (since the echo period is truly the time it receipts the sound to go there and back) [11]. The ultrasonic parking sensor device is shown in Figure 3.

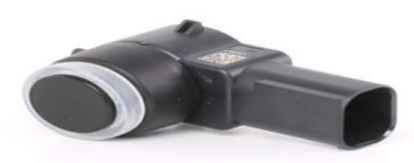

Figure 3. An ultrasonic parking sensor 
From Table 2 we see that the technical specification of an ultrasonic parking sensor. We see that the range of a typical ultrasonic parking sensor lies between 0.3 to 2 meters, beam-width horizontally as well as vertically greater than 60 degrees, beam-pattern are conical, and frequency of an ultrasonic sensor typically ranges from 315 mega-hertz to 433 mega-hertz. The unit cost is 30 INR.

Table 2. Technical specification of sensors $[12,13]$

\begin{tabular}{cc}
\hline Parameters & Ultrasonic Parking Sensor \\
\hline Range & $0.3 \sim 2 \mathrm{~m}$ \\
Beam-width & $\mathrm{H}>60, \mathrm{~V}>60$ degree \\
Beam Pattern & Conical \\
Frequency & $315 \mathrm{MHz} / 433 \mathrm{MHz}$ \\
Unit Cost & $30 \mathrm{INR}$. \\
\hline
\end{tabular}

\subsection{Raspberry Pi4}

Raspberry Pi4 is a debit card sized single-board PC with an OS Raspbian mounted [14, 15]. Raspberry Pi 4's specifications are specified in Table 03. The Raspberry accumulates the quantity of parking slots from apiece NodeMCU V3 and processes the information as well as up to date the database server with a total number of empty slots. Figure 4 displays the existing interfaces in Raspberry Pi 4.

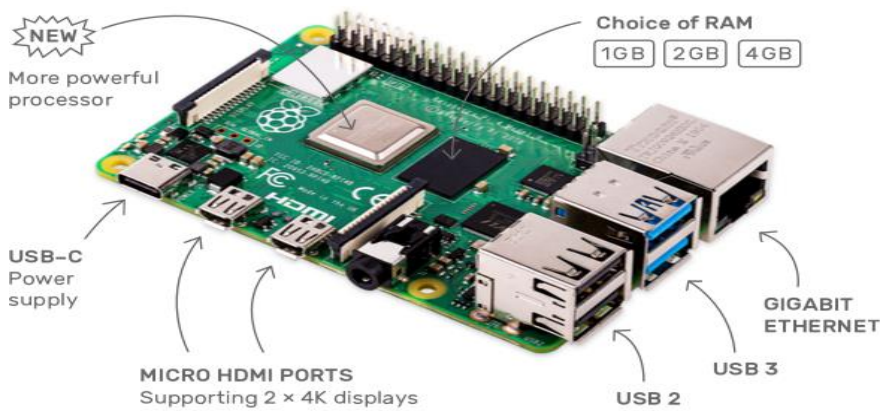

Figure 4. Raspberry Pi4 boards

Table 3 displays the specifications of a Raspberry Pi 4 device. From the table, we see that the Raspberry pi 4 board contains a dual-core 64 bit SoC processor. It has an option of RAM like 1 GB, 2GB, or 4 GB. Users can choose 1GB, 2 GB, or 4 GB RAM depending on their architecture. The number of Universal Serial Ports is 4, two USB are 3.0 ports and two are 2.0 ports. A typical Raspberry Pi 4 also contains 40 GPIO pins. It has a Gigabyte Ethernet port for internet connections. The additional features of a Raspberry Pi 4 boards are 2 micro HDMI ports, 2 display ports, 2 camera ports, micro SD card slots as well as a Linux based Operating System.

Table 3. Raspberry pi4 specifications [15]

\begin{tabular}{|c|c|}
\hline Specifications & Values \\
\hline Central Processing Unit & Broadcom BCM 2711, Dual core Cortex-A72 (ARM v-8) 64-bit SoC @ $1.5 \mathrm{GHz}$ \\
\hline Random Access Memory & $1 \mathrm{~GB}, 2 \mathrm{~GB}$ or 4GB LP DDR 4-2400 SDRAM \\
\hline Universal Serial Bus Ports & 2 USB 3.0 ports; 2 USB 2.0 ports \\
\hline GPIO Pins & Raspberry Pi typical 40 pin \\
\hline \multirow{7}{*}{ Additional Features } & 1. HDMI $-2 \times$ micro-HDMI ports (up to $4 \mathrm{k} \times 60$ supported) \\
\hline & Display port - 2-lane MIPI DSI \\
\hline & Camera port - 2-lane MIPI CSI \\
\hline & Audio - 4-pole stereo audio and combined video port \\
\hline & Storage - Micro-SD card slot for loading OS and data storage \\
\hline & $\begin{array}{l}\text { 6. Misc - H.265 (4k x } 60 \text { decode), H.264 (1080 x } 60 \text { decode, } 1080 \text { x } 30 \text { encode), } \\
\text { OpenGL ES } 3.0 \text { visual aid. }\end{array}$ \\
\hline & OS-Debian Linux 10 centered \\
\hline
\end{tabular}




\section{PERFORMANCE ANALYSIS}

As of the following assessed chart Figure 5 it is plainly shows that our system will be progressively effective then the other existing system. From Figure 5, it is clear our proposed smart car parking system requires less an ideal opportunity to scan for a free space when contrasted with that of ordinary pursuit. In typical inquiry client sets aside part of effort to discover the accessible space. Be that as it may, in our proposed strategy we have a choice of prebooking, which spares time [16-25].

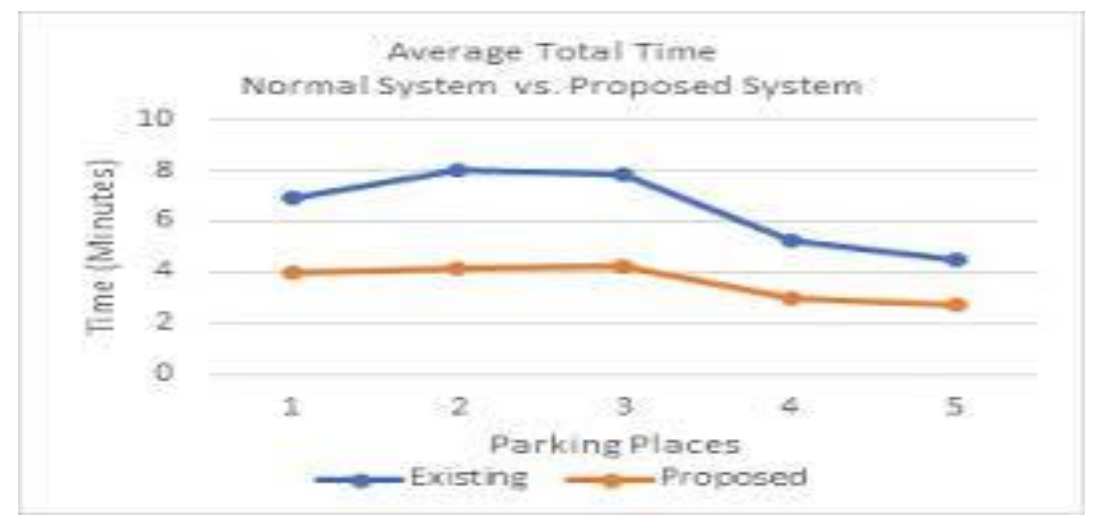

Figure 5. Performance comparison with existing system

\section{CONCLUSION}

Smart City operation is the prime object of the Government of Bangladesh. The Government's plan is to improve fifteen smart towns all over the state. Nowadays data can be accessed anywhere and on any device with the aid of quick development in the Internet of Things (IoT) and cloud computing paradigm. This article addresses an online-based parking reservation, and supervision, entrance, and leaving methods are presented to resolve the parking problems in Dhaka town and for setting out in Smart Towns. By using a cell phone's iOS application operator can reserve a parking slot whenever he/she likes as well as from any spot.

\section{ACKNOWLEDGEMENTS}

All praise and thanks are to ALLAH Almighty. After that, I would like to express my profound appreciation concerning my supervisor, Professor Dr. Yun Li for his endless supervision, promising assistance as well as motivating disputes. I am obliged to the School of Information and Communications Engineering for their livelihood.

\section{REFERENCES}

[1] Gandhi, B. K., \& Rao, M. K., “A prototype for IoT based car parking management system for smart cities,” Indian Journal of Science and Technology, vil. 9, no. 17, pp. 1-6, 2016.

[2] D. Vakula and Y. K. Kolli, "Low cost smart parking system for smart cities," 2017 International Conference on Intelligent Sustainable Systems (ICISS), Palladam, pp. 280-284, 2017.

[3] Atiqur, R., \& Li, Y, “Automated smart car parking system using raspberry Pi 4 and iOS application," International Journal of Reconfigurable and Embedded Systems IJRES, vol. 9, no. 3, pp. 229-234, 2020.

[4] Yanxu Zheng, S. Rajasegarar and C. Leckie, "Parking availability prediction for sensor-enabled car parks in smart cities," 2015 IEEE Tenth International Conference on Intelligent Sensors, Sensor Networks and Information Processing (ISSNIP), Singapore, pp. 1-6, 2015.

[5] A. Khanna and R. Anand, "IoT based smart parking system," 2016 International Conference on Internet of Things and Applications (IOTA), Pune, pp. 266-270, 2016.

[6] A. Roy, J. Siddiquee, A. Datta, P. Poddar, G. Ganguly and A. Bhattacharjee, "Smart traffic \& parking management using IoT," 2016 IEEE 7th Annual Information Technology, Electronics and Mobile Communication Conference (IEMCON), Vancouver, BC, pp. 1-3, 2016.

[7] T. N. Pham, M. Tsai, D. B. Nguyen, C. Dow and D. Deng, "A Cloud-Based Smart-Parking System Based on Internet-of-Things Technologies," in IEEE Access, vol. 3, pp. 1581-1591, 2015.

[8] Zerynth, [Online]. Available: https://docs.zerynth.com/latest/official/board.zerynth.nodemcu3/docs/index.html

[9] Autogeekonline, [Online]. Available: https://www.autogeekonline.net/forum/ask-mike-phillips-your-etailingquestions-/28546-ultrasonic parking-sensor-principle.html 
[10] M.B.Ahmad, A.A.Abdullahi, A.S.Muhammad, Y.B.Saleh, U.B.Usman, "The Various Types of sensors used in the Security Alarm system" International Journal of New Computer Architectures and their Applications IJNCAA, vol. 9, no. 2, pp. 50-59, 2019.

[11] M. B. Ahmad, M. Cavas, "A review advancement of security alarm system using internet of things (IoT)" International Journal of New Computer Architectures and their Applications, vol. 9, no. 2, pp. 38-49, 2019.

[12] [Online]. Available: https://www.parkingsensors.co.uk/page/technical-specifications

[13] A. Dimitrov and D. Minchev, "Ultrasonic sensor explorer," 2016 19th International Symposium on Electrical Apparatus and Technologies (SIELA), Bourgas, pp. 1-5, 2016.

[14] Raspberry Pi 4 Documentation, [Online]. Available: https://www.raspberrypi.org/

[15] Raspberry Pi 4 Configuration, [Online]. Available: http://www.databook.bz/?cat=56"

[16] Rahman A, Yun L, Ali Md L, “Automated Smart Car Parking System Using Internet of Things (IoT) Technology for Smart Cities Demand," North American Academic Research, vol. 3, no. 8, pp. 7-19, 2020

[17] A. Khanna and R. Anand, "IoT based smart parking system," 2016 International Conference on Internet of Things and Applications (IOTA), Pune, pp. 266-270, 2016.

[18] W. Alsafery, B. Alturki, S. Reiff-Marganiec and K. Jambi, "Smart Car Parking System Solution for the Internet of Things in Smart Cities," 2018 1st International Conference on Computer Applications \& Information Security (ICCAIS), Riyadh, pp. 1-5, 2018.

[19] M. Fraifer and M. Fernström, "Smart car parking system prototype utilizing CCTV nodes: A proof of concept prototype of a novel approach towards IoT-concept based smart parking," 2016 IEEE 3rd World Forum on Internet of Things (WF-IoT), Reston, VA, pp. 649-654, 2016.

[20] Mudaliar, Shruthi, Sujay Mudhol, Chaitanya K Jambotkar, "IoT based smart car parking system," International Journal for Science and Advance Research In Technology, vol. 5, no. 1, 270-272, 2019.

[21] Natarajan, P. B., and Samit Kumar Ghosh, "Design and implementation of smart car parking system using lab view," International Journal of Pure and Applied Mathematics, vol. 120, no. 6, pp. 329-338, 2018

[22] Bachhav, Jayakshei Dadaji, and M. A. Mechkul, "Smart car parking system," International Research Journal of Engineering and Technology, vol. 4, no. 6, pp. 3036-3038, 2017.

[23] Nandyal, Suvarna, Sabiya Sultana, and Sadaf Anjum, "Smart car parking system using arduino uno," International Journal of Computer Applications, vol. 169, no. 1, pp. 13-18, 2017.

[24] B. M. Mahendra, S. Sonoli, N. Bhat, Raju and T. Raghu, "IoT based sensor enabled smart car parking for advanced driver assistance system," 2017 2nd IEEE International Conference on Recent Trends in Electronics, Information \& Communication Technology RTEICT, Bangalore, pp. 2188-2193, 2017.

[25] P. Sadhukhan, "An IoT-based E-parking system for smart cities," 2017 International Conference on Advances in Computing, Communications and Informatics ICACCI, Udupi, pp. 1062-1066, 2017.

\section{BIOGRAPHIE OF AUTHORS}

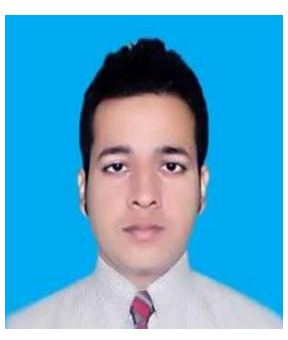

Mr. Rahman Atiqur received his Bachelor of Science (B.Sc) and Master of Engineering (M.Engg.) degree from the Department of Computer Science and Engineering at the University of Chittagong, Chittagong, Bangladesh. In profession, he worked in the Department of Computer Science and Engineering, University of Chittagong, Bangladesh as an Assistant Professor since April 2016. Former he was a lecturer in the Department of Computer Science and Engineering, University of Chittagong, Bangladesh. He is now conducting his Ph.D. research works under the Chinese Government Scholarships (CGS) Program at Chongqing University of Posts and Telecommunications, Chongqing, China. His current research interest lies in the field of edge computing-based IoT systems. 